\title{
Renal bladder ultrasound in children with urinary tract infection
}

\begin{tabular}{c}
\hline Gabriel C. Dragan \\
Pediatric Surgery, "Dr. Victor Gomoiu” Clinical Hospital for Children, Bucharest \\
\hline
\end{tabular}

\begin{abstract}
Introduction. Urinary tract infections (UTI) are a common problem in the pediatric age patients. They can represent the first sign of congenital anomaly of the kidney or urinary tract (CAKUT) in children younger than 2 years, vesicoureteral reflux being the most frequent. Renal bladder ultrasound (RBUS) is the most utilized imaging modality in children with UTI. RBUS is a non-invasive, non-radiating and the least expensive imaging test available.

Materials and methods. The present study is a retrospective analysis of patients admitted for UTI in "Grigore Alexandrescu" Clinical Emergency Hospital for Children between 1st January 2015 and 31st December 2017. Results. RBUS was performed in 310/359 cases. Urinary tract anomalies were found in 108 patients. In 67/108 cases upper urinary tract dilations were identified. $31 / 191$ patients $(16 \%)$ under 2 years of age had upper urinary tract dilations on RBUS, while $36 / 119$ patients $(30 \%)$ older than 2 years had positive RBUS for upper urinary tract dilations. In 61 cases both RBUS and VCUG were available. 11/29 patients with upper urinary tract dilations on RBUS had VUR on VCUG (8 patients with high grade VUR). 8 patients with normal RBUS had VUR on VCUG (5 patients with high grade VUR).

Conclusions. Although RBUS is a non-invasive and non-radiating imaging test, its value when used alone in children with UTI is limited in diagnosing CAKUT, especially VUR.
\end{abstract}

Keywords: urinary tract infection, children, ultrasound

\section{INTRODUCTION}

Urinary tract infections (UTI) are a common problem in the pediatric age patients $(1,2)$. The prevalence of UTIs is estimated to be $7-10 \%$ of infants under the age of 2 years presenting with fever with no apparent reason. The prevalence and clinical manifestations of UTIs depend on the age and sex of the patient. Thus, the incidence is higher in boys under 6 months, while girls older than 6 months have a higher incidence of UTI $(1,3)$. UTIs have high morbidity and can lead to serious longterm complications, like renal scarring, arterial hypertension and chronic kidney disease (CKD) (4). They can represent the first sign of congenital anomaly of the kidney or urinary tract (CAKUT) in children younger than 2 years, vesicoureteral reflux being the most frequent (5). Recurrent UTIs and the risk of renal scarring and CKD are an indication for the diagnosis and treatment of UTIs and of possible CAKUT $(1,5,6)$.
Imaging of the urinary tract in children with UTI reveal congenital anomalies of the urinary tract in $20-80 \%$ of cases (6). On the other hand, the impact of a congenital anomaly discovered after an UTI is not well studied. Diagnosis of these anomalies is reasonable only if their treatment can significantly reduce the incidence of UTIs and their complications (7).

Renal bladder ultrasound (RBUS) is the most utilized imaging modality in children with UTI. RBUS is a non-invasive, non-radiating and the least expensive imaging test available. It provides important information on the dimensions and shape of the kidneys, and on the presence of dilations of the urinary tract. RBUS can also identify renal or perirenal abscesses and pyonephrosis in children with UTI and unfavorable outcome under antibiotic treatment $(8,9,10)$.

Although RBUS can be a useful tool in diagnosing structural anomalies of the kidney and urinary 
tract, using only RBUS in evaluating febrile UTIs in children is not recommended, one third of low grade VUR patients being missed $(3,8)$.

The purpose of this study is to evaluate renal bladder ultrasound as an imaging test in children with UTI.

\section{MATERIALS AND METHODS}

The present study is a retrospective analysis of patients admitted for UTI in "Grigore Alexandrescu" Clinical Emergency Hospital for Children between $1^{\text {st }}$ January 2015 and $31^{\text {st }}$ December 2017.

Inclusion criteria were age under 18 years and UTI diagnosis. Children with previously diagnosed urinary tract anomalies were excluded.

Data were collected from the informatic system of the hospital and were analyzed with Microsoft ${ }^{\circledR}$ Excel (ver. 16.15) and IBM ${ }^{\circledR}$ SPSS ${ }^{\circledR}$ Statistics (ver. 25).

\section{RESULTS}

Between $1^{\text {st }}$ January 2015 and $31^{\text {st }}$ December 2017 there were 826 patients admitted for UTI. Of those, 359 were included in the study (confirmed or possible UTI). There were $211 / 359$ girls (58.8\%). The mean age was 44.76 months, with a minimum of 4 days and a maximum of 17.9 years.

$227 / 359$ were under 2 years of age at the time of admission, 111 girls and 116 boys. In the older than
2 years of age group there were 132 patients, 100 girls and 32 boys $(\mathrm{p}<0.001)$ (Figure 1$)$.

RBUS was performed in 310/359 cases. Urinary tract anomalies were found in 108 patients. In 41 cases there were only bladder anomalies (bladder wall thickening or bladder debris). In the other $67 / 108$ cases upper urinary tract dilations were identified (44 cases of pyelocaliceal dilation, 17 cases of pyelocaliceal and ureteral dilation and 6 cases of ureteral dilation) (Figure 2).

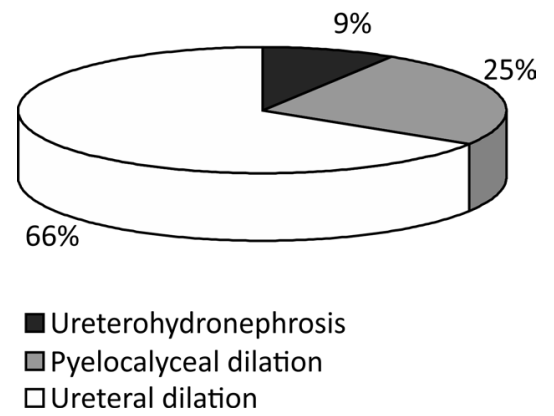

FIGURE 2. Renal bladder ultrasound anomalies

$59 / 184$ girls (32\%) and 49/126 boys (39\%) respectively, had a positive RBUS ( $>>0.05$ ). 31/191 patients $(16 \%)$ under 2 years of age had upper urinary tract dilations on RBUS, while $36 / 119$ patients $(30 \%)$ older than 2 years had positive RBUS for upper urinary tract dilations $(\mathrm{p}<0.05)$ (Table 1$)$.

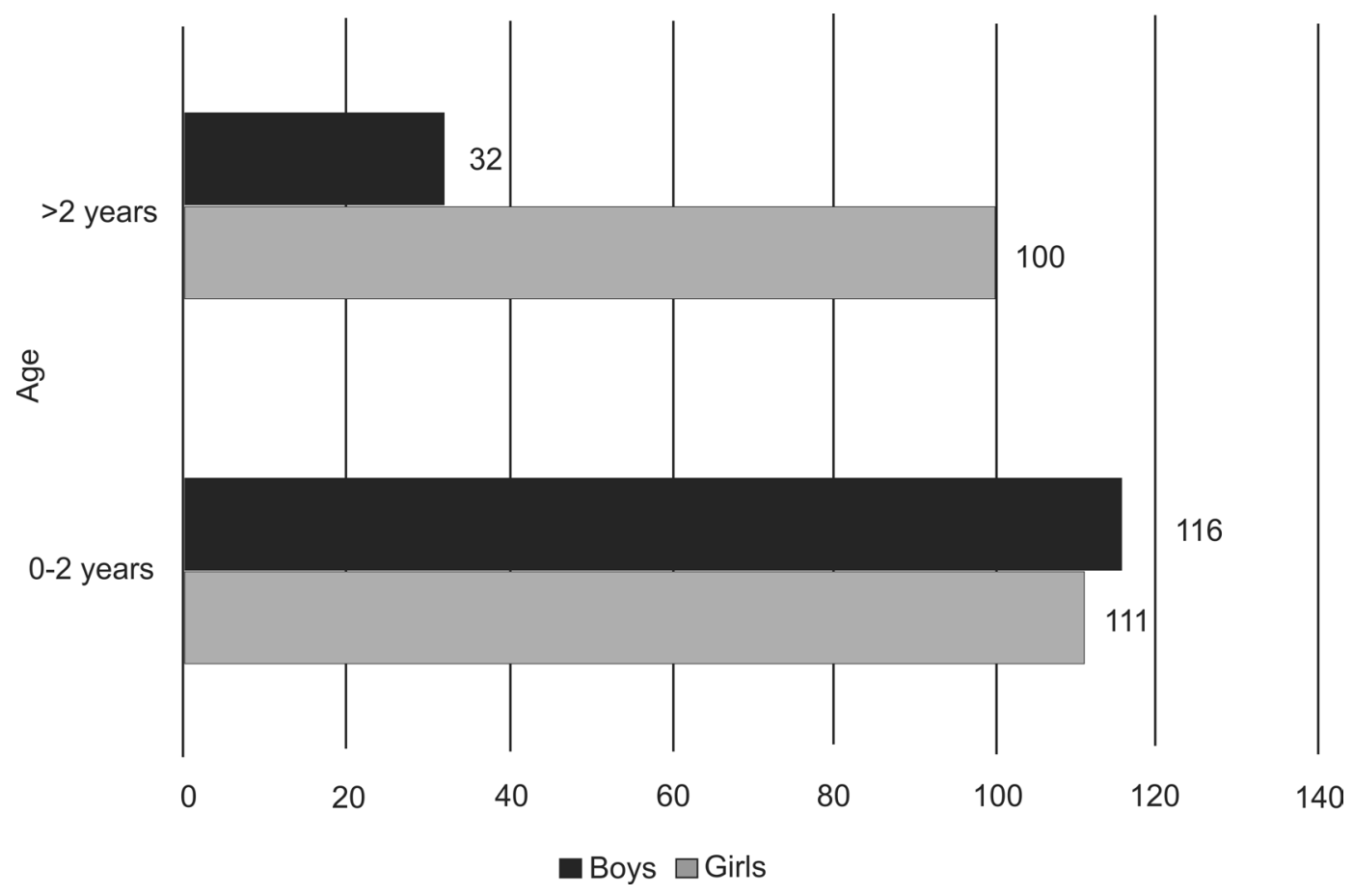

FIGURE 1. Sex distribution depending on age group 
TABLE 1. RBUS findings depending on age of patient

\begin{tabular}{|l|c|c|c|c|}
\hline \multicolumn{2}{|l|}{} & \multicolumn{2}{|c|}{ Renal bladder ultrasound } & \multirow{2}{*}{ Total } \\
\cline { 2 - 4 } \multicolumn{2}{|c|}{} & Normal & $\begin{array}{c}\text { Upper urinary tract } \\
\text { dilations }\end{array}$ & \\
\hline \multirow{2}{*}{ Age } & $\mathbf{0}-\mathbf{2}$ years & 160 & 31 & 191 \\
\cline { 2 - 4 } & $\mathbf{2}$ years & 83 & 36 & 119 \\
\hline \multicolumn{2}{|l|}{ Total } & 243 & 67 & 310 \\
\hline
\end{tabular}

Voiding cystourethrography (VCUG) was performed in 66 cases. In 61 cases both RBUS and VCUG were available. 11/29 patients with upper urinary tract dilations on RBUS had VUR on VCUG ( 8 patients with high grade VUR). 8 patients with normal RBUS had VUR on VCUG (5 patients with high grade VUR) $(\mathrm{p}>0.05)$ (Table 2).

TABLE 2. RBUS findings depending on VUR grade

\begin{tabular}{|c|c|c|c|c|c|}
\hline & \multicolumn{3}{|c|}{ Vesicoureteral reflux } & \multirow[b]{2}{*}{ Total } \\
\hline & & $\begin{array}{l}\text { No } \\
\text { VUR }\end{array}$ & $\begin{array}{c}\text { VUR } \\
\text { grade } \\
\text { I-II } \\
\end{array}$ & $\begin{array}{c}\text { VUR } \\
\text { grade } \\
\text { III-V }\end{array}$ & \\
\hline \multirow{2}{*}{$\begin{array}{l}\text { Renal } \\
\text { bladder } \\
\text { ultrasound }\end{array}$} & Normal & 24 & 3 & 5 & 32 \\
\hline & $\begin{array}{l}\text { Upper urinary } \\
\text { tract dilations }\end{array}$ & 18 & 3 & 8 & 29 \\
\hline \multicolumn{2}{|l|}{ Total } & 42 & 6 & 13 & 61 \\
\hline
\end{tabular}

\section{DISCUSSIONS}

RBUS is the most frequently used imaging test in children with UTI, although its value is strongly debated, with low sensitivity and specificity in the diagnosis of CAKUT. In 2011, the American Academy of Pediatrics (AAP) recommended RBUS in all children under the age of 2 with UTI (11). The National Institute of Health and Care Excellence guidelines from 2007 (updated in 2013 and 2017) recommend RBUS only in selected cases of children with UTI (non-Escherichia coli UTI, non-favourable outcome with antibiotic treatment, age under 6 months) (12). In our study, RBUS was performed in $86 \%$ of cases and was normal in $65 \%$ of patients. Upper urinary tract dilations leading to changes in the management plan of the patient (adding other imaging tests or ultrasound monitoring) were found in $21 \%$ of patients $(67 / 310)$. These findings confirm the findings of Preda et al. who found an incidence of $41 \%$ in ultrasound urinary tract anomalies in children with UTI (13). Suson et al. found a similar incidence (14), while Nelson et

\section{REFERENCES}

1. Prajapati $\mathrm{H}$. Urinary tract infections in children. Paediatr. Child Heal. (United Kingdom). 2018;28:318-323.

2. Copp HL, Schmidt B. Work up of pediatric urinary tract infection. Urol Clin North Am. 2015;42:519-526. al. reported a lower incidence, of $25 \%$ of urinary tract anomalies on RBUS in children with UTI (15).

While there were no significant differences between girls and boys regarding RBUS findings, we noticed a significant difference between patients under and older 2 years of age. Although most studies report an increased incidence of CAKUT in children under the age of 2 with UTI $(5,11)$, in our study we observed that most urinary tract anomalies were found in the older children group. This finding can be explained by the exclusion of children with previously diagnosed anomalies, including those diagnosed antenatally. This leads to an increase of the number of children with CAKUT who are diagnosed later in childhood, at the moment of UTI.

We analysed the value of RBUS in identifying patients with VUR. There was a high number of patients with normal RBUS that were diagnosed with VUR on VCUG, including 5 patients $(16 \%)$ with high grade VUR (III-V). Although the results were not statistically significant given the small sample size, the number of patients that would benefit from treatment of VUR and were missed on RBUS is still high. Thus, we can suggest that RBUS has limited value in identifying patients with VUR.

The limits of this study include its retrospective and observational nature. Another limit is the number of patients included in the study. Although the data are comparable to other studies, the number of patients with abnormal RBUS is low, thus, the statistical significance is also low. RBUS is a subjective, operator dependent imaging study. Although all the imaging studies were done by experienced pediatric radiologists, this disadvantage of RBUS cannot be overlooked.

\section{CONCLUSIONS}

Although RBUS is a non-invasive and non-radiating imaging test, its value when used alone in children with UTI is limited in diagnosing CAKUT, especially VUR. We recommend the use of combined imaging tests in selected patients to diagnose urinary tract anomalies. Further studies on larger groups are needed to establish the correlation between imaging tests in children with UTI.

Conflict of interest: none declared Financial support: none declared

3. Hannula A, Venhola M, Perhomaa M et al. Imaging the urinary tract in children with urinary tract infection. 2012;100.

4. Madhi $F$ et al. Febrile urinary-tract infection due to extendedspectrum beta-lactamase-producing Enterobacteriaceae in children: 
A French prospective multicenter study. PLoS One. 2018; 13:1-14.

5. Okarska-Napierała M, Wasilewska A, Kuchar E. Urinary tract infection in children: Diagnosis, treatment, imaging - Comparison of current guidelines. J. Pediatr. Urol. 2017;13:567-573.

6. Palacios Loro ML, Segura Ramirez DK, Ordonez Alvarez FA et al. Congenital anomalies of the kidney and urinary tract. A vision for the paediatrician. An Pediatr (Barc). 2015;83:442e1-442e5.

7. Vachvanichsanong $P$, Dissaneewate $P, M c N e i l E$. What Did We Find From Imaging Studies in Childhood Urinary Tract Infection and Which Studies Are Mandatory?. Urology. 2018;111:176-182.

8. Tsai I. The Role of Renal Ultrasound in Children with Febrile Urinary Tract Infection. Pediatr. Neonatol. 2016;57:83-84.

9. Ghobrial EE, Abdelaziz DM, Sheba MF et al. Value of Ultrasound in Detecting Urinary Tract Anomalies after First Febrile Urinary Tract Infection in Children. Clin. Pediatr. (Phila). 2015;55:415-420.

10. Jadresic L. Urinary tract infections in children. Paediatrics and child health. 2014;24:289-292.
11. Subcommittee on Urinary Tract Infection, Steering Committee on Quality Improvement and Management, Roberts KB. Urinary tract infection: clinical practice guideline for the diagnosis and management of the initial UTI in febrile infants and children 2 to 24 months. Pediatrics. 2011;128:595-610.

12. National Institute for Health and Care Excellence. Urinary tract infection in children: diagnosis, treatment and long-term management. 2007.

13. Preda I, Jodal U, Sixt $R$ et al. Value of Ultrasound in Evaluation of Infants With First Urinary Tract Infection. JURO. 2010;183:1984-1988.

14. Suson KD, Mathews R. Evaluation of children with urinary tract infection - Impact of the 2011 AAP guidelines on the diagnosis of vesicoureteral reflux using a historical series. J. Pediatr. Urol. 2014;10:182-185.

15. Nelson C, Chow J, Johnson E et al. Test characteristics and predictive value of ultrasound as a screening test for $\mathrm{GU}$ anomalies among children presenting with UTI. J. Urol. 2013;189:266. 